\title{
A pedagogia artística como normação da vida: tecnologias do eu e produção do génio musical em Portugal (final do século XIX a início do século XX)
}

\section{Arts pedagogy as life's norm-making: Technologies of the self and the production of musical genius in Portugal (end of the $19^{\text {th }}$ to the begging of the $20^{\text {th }}$ century)}

\author{
Ana Luísa Paz* \\ Jorge Ramos do Ó*
}

\begin{abstract}
RESUMO
Esta discussão sobre educação e ensino musical português, entre final do século XIX e início do século XX - uma época em que a procura das aprendizagens musicais foi rarefeita - procura introduzir a hipótese de uma leitura biopolítica a partir da tecnologia do génio. Esse conceito atravessou diversos ramos de ensino, embora através de diferentes modalidades - o que permite perguntar se a regulação artística das populações se daria por uma mesma tecnologia. A pergunta surge a partir da identificação dos diversos contextos educativos, práticas pedagógicas e incidências artísticas que parecem bifurcar o génio em nacional e individual. A educação musical (ensino primário, secundário e normal) foi incentivada pelo Estado através das práticas de canto coral, então, também designado por canto escolar, e com possibilidade de abranger toda a população. Para a grande massa, agilizou-se a incorporação do génio nacional - com suas manifestações públicas de repertório musical, linguístico, emocional e corporal. O ensino musical especializado (conservatórios) dirigia-se, porém, a uma pequena parcela da população, a qual seria capacitada para a execução e criação musical. $\mathrm{O}$
\end{abstract}

* Universidade de Lisboa. Instituto de Educação. Lisboa, Portugal. Alameda da Universidade MB Contato: apaz@campus.ul.pt; jorge.o@ie.ulisboa.pt. 
incentivo do génio musical (individual) repercutiu uma produtividade global de rarefação das oportunidades, sendo possível identificar algumas dessas técnicas a partir da pedagogia de instrumentos de grande procura, como o piano. Currículos e práticas escolares remetem, apesar desta diferenciação, para o génio como tecnologia unívoca, agilizada por diferentes técnicas pedagógicas de normação dos sujeitos.

Palavras-chave: Ensino musical. Canto coral. Currículo. Tecnologias do eu. Génio.

\begin{abstract}
This discussion about Portuguese music education, between the end of the $19^{\text {th }}$ century and the beginning of the $20^{\text {th }}$ century, a time when the demand for musical learning was rarefied, seeks to introduce the hypothesis of a biopolitical understanding of the technology of genius. This concept crossed several branches of education, albeit through different modalities - which allows us to ask whether the artistic regulation of the populations was conducted by the same technology. The question arises from the identification of different educational settings, pedagogical practices and artistic incidences that seem to bifurcate the genius into national and individual. Music education (primary, secondary and normal) was encouraged by the State through choral singing practices, given its possibility of reaching the entire population. For the great mass, the incorporation of the national genius was enabled - with its public manifestations of musical, linguistic, emotional, and corporal repertoire. Conservatoire music education was directed, however, to a small part of the population, which would be qualified for musical execution and creation. The incentive of (individual) musical genius reflected a global productivity of rarefaction of opportunities, allowed for the identification of some of these techniques possible within the pedagogy of instruments of great demand, such as the piano. Thus, despite this differentiation, curricula and school practices refer to genius as a univocal technology, facilitated by different pedagogical techniques of subject regulation.
\end{abstract}

Keywords: Music education. Chorus singing. Curriculum. Technologies of the self. Genius. 


\section{Introdução}

O modelo biopolítico sofreu uma enorme aceleração a partir do século XVIII, com a crescente afinação das estratégias de poder-saber que apetrecharam o emergente Estado-nação com um dispositivo, tornado cada vez mais ágil, para o governo da população no seu conjunto, permitindo o seu aperfeiçoamento ético e estético. No caso português aqui observado, temos por hipótese que, entre final do século XIX e início do século XX, o Estado conduziu o destino de setores da população a determinadas aprendizagens musicais, introduzindo o conceito "génio", de circulação internacional, como tecnologia capaz de atuar através de estratégias pedagógicas, mais ou menos avulsas, sobre os alunos de educação musical (ensino primário, secundário e normal) e de ensino especializado (conservatório). Todos seriam subjetivados por este conceito, que, como um regulador interno, inscreveria uma norma por natureza impossível de inscrever.

O Estado, através das propostas curriculares para a educação musical nas escolas primárias, secundárias e normais, bem como da oferta formativa garantida pelo Conservatório de Lisboa (única escola oficial por mais de um século), pretendeu incentivar, mas também conduzir, o desejo de ser artista. De uma só assentada, refreava e impulsionava o sujeito em direção às práticas que fariam dele ora um músico ora um ouvinte, implicando uma hierarquia e um sistema de relações e exclusões mútuas. Neste artigo, apontamos assim o génio musical como uma tecnologia do eu, capaz de disciplinar tanto as condutas das massas, como dos próprios indivíduos reconhecidos como génios musicais - aqueles cuja subjetivação os levou a almejar e a concretizar a diferença absoluta.

Para observar a irrupção desta estratégia biopolítica no contexto português, sugerimos as barreiras legislativas de 1868 e 1930. O decreto de 31 de dezembro de 1868 reforma a instrução primária, secundária e superior, o Conservatório Real de Lisboa, as Academias de Belas Artes, o Curso Superior de Letras e as bibliotecas públicas, constituindo-se como um primeiro suporte para o alargamento das formações artísticas. Por sua vez, o decreto com força de lei $\mathrm{n}^{\circ} 18.461$, de 14 de junho de 1930, que reforma o Conservatório Nacional de Música e o Conservatório Nacional de Teatro, determinado que passem a constituir o Conservatório Nacional, em conjunto com o decreto $\mathrm{n}^{\circ} 18.881$, de 25 de setembro de 1930, que aprova a reorganização da nova instituição, vem fechar este ciclo, impondo numerus clausus, como forma de contenção no acesso ao ramo especializado. Nesse espaço de tempo, que corresponde ao tempo de implementação e disseminação de práticas de ensino musical nos diversos ramos de ensino português, o génio foi também tecnologicamente aperfeiçoado. 


\section{Revisão de literatura: desde a governamentalidade às possibilidades da biopolítica}

O problema gizado reverte da confluência de duas perspetivas. De uma parte, repercute os estudos biopolíticos em Educação sobre os dispositivos que, desde o final do século XVIII, trabalharam na Europa a disciplina dos corpos. De outra parte, reivindica-se, na linha da genealogia da Educação e Ensino Artístico, que se tem debruçado acerca dos mecanismos de rarefação das oportunidades de aprendizagens.

Em primeiro lugar, salienta-se a especificação da biopolítica, tomada como um exercício de poder que congrega várias técnicas numa única tecnologia (FOUCAULT, 1994). Insere-se nos estudos da governamentalidade, neologismo lançado desde análises do poder de Vigiar e Punir, e que têm viabilizado a identificação de modus operandi do conjunto de instituições, práticas e formas de pensamento peculiares a uma forma específica de exercício de poder sobre a população. Por sua vez, esse é assegurado pelo saber-poder da economia política e pelos instrumentos técnicos que operam enquanto dispositivos de segurança. Governamentalidade, no sentido mais próximo ao tema aqui visado, reverte de um foco mais específico sobre a "tendência" que, por "todo o Ocidente", se impôs na condução "em direção à preeminência desse tipo de saber que se pode chamar "governo" sobre todos os outros: soberania, disciplina", com o paralelo "desenvolvimento" de "aparelhos específicos de governo" e de "saberes" (FOUCAULT, 2006, p. 303). Este entendimento (FOUCAULT, 1994) é aqui convocado para examinar a norma musical pedagógica agindo sobre os corpos dos indivíduos da modernidade.

No caso português, as tópicas foucaultianas têm sido trabalhadas desde a genealogia do liceu moderno (Ó, 2003), que lançou as bases teóricas e metodológicas para uma história crítica e analítica. Catarina Martins (2011) perlustrou a ideia de génio como invariante do ensino moderno das artes visuais portuguesas, tema aprofundado por Helena Cabeleira (2013) sobre o aluno artista no âmbito das atividades universitárias. Nessas investigações, as tecnologias de si reverberadas no génio surgem agregadas ao estatuto sociocultural, que hierarquiza as disposições estéticas e artísticas. O mesmo dispositivo de rarefação pode ser observado no ensino especializado de música, em que o conceito interfere tanto nas relações calibradas pela pedagogia quanto na psicologia e na expertise musical strictu sensu. Os sujeitos passaram a depender de conceitos-satélite de génio que os descreveram e inscreveram nas suas práticas, e que no limite seriam capazes de os conduzir ou não ao devir-artista, tais como talento, dom, aptidão, 
habilidade, níveis de performance, precocidade, herança, personalidade e, com uma importância crescente durante o século XX, criatividade (PAZ, 2014).

\section{Linhas teóricas e conceituais: técnicas do eu no ensino de música}

A linhagem teórica e empírica, a que nos afiliamos, permite-nos suspeitar de como o conceito de génio foi apropriado pelo Estado, e de que modo foi ressignificado pelos indivíduos englobados na teia do ensino musical. Em outras palavras, a nossa discussão incide sobre a capacidade dessa tecnologia de intervir sobre as decisões de carreira artística e suportar ou excluir os indivíduos das práticas musicais.

Por tecnologias do eu, referia-se Foucault ao conjunto de técnicas performativas de poder que incitaram o sujeito a agir e a operar modificações sobre a sua alma e corpo, pensamento e conduta, procurando vinculá-lo a uma atividade de constante vigilância e de adequação permanente aos princípios morais em circulação na sua época. Subjetivação, tal como no-la apresenta o filósofo francês, envolve exercícios de inibição do eu, ligados às dinâmicas políticas de governo e ao desenvolvimento de formas de conhecimento científico. Por essa via, a sociedade moderna transformou-se numa sociedade essencialmente disciplinar (Ó, 2003). Segundo essa proposta, a formação do homem moderno desenvolveu-se através dos mecanismos por intermédio dos quais cada um se relaciona consigo mesmo, desenvolvendo uma autêntica arte de existência destinada a reconhecer-se a si como um determinado tipo de sujeito. Compreende-se assim como, para ele, a ética torna-se unicamente inteligível como um domínio da prática e, por consequência, também o seu devir estético.

Consideramos que o conceito civilizacional de génio pode ser aqui entendido como "palavra total, prismática ou até mesmo caleidoscópica, onde cabem quaisquer descrições, até a da normalidade, essa que apenas se define pela exceção à qual alude" (PAZ, 2014, p. 284), pois “para o génio ainda ninguém descobriu a condição suficiente" (SERRES, 2005, p. 23). Este termo remete, na nossa hipótese, para uma tecnologia unívoca onde confluem as diferentes técnicas de agenciamento dos sujeitos. Consideramos que são introduzidas e aperfeiçoadas, no interior mesmo das práticas escolares, diversas técnicas que aproximam ou afastam a possibilidade de ser músico. Como referem diversos estudos, existe uma noção comum de ser "não-musical", intimamente ligada a perceções acontecidas no interior da escola e relacionada com as primeiras aprendizagens musicais (RUDDOCK; LEONG, 2005, p. 20). Reportamo-nos, 
assim, constantemente, a dispositivo escolar propriamente dito entendido aqui, num prolongamento da ideia original de Foucault (1994), como o aparato que teria o poder de moldar gestos, ações e condutas opiniões (AGAMBEN, 2009, p. 40) sustentando a rarefação do ensino musical - muito para lá de impedimentos de género, classe socioeconómica, raça.

\section{História do presente e séries documentais}

A vocação histórica desta problemática levou-nos a assumir uma história do presente (FOUCAULT, 2004), considerando aqui uma investigação genealógica, de acordo com as propostas de Friedrich Nietzsche desenvolvidas por Michel Foucault (1984). Considera-se ser um método que utiliza a história para entender o presente, que assume uma ênfase na interação contínua durante a elaboração de teorias e hipóteses e que tenta refletir sobre o posicionamento do pesquisador (VARELA, 2001, p. 108). Enfatiza a relação entre os poderes e o corpo, que é considerado a superfície onde se inscrevem os eventos (FOUCAULT, 1984, p. 83). A genealogia tem assim como incumbência "expor o corpo", mostrando como ele foi "totalmente impresso pela história". A perspetiva histórica é alcançada através da identificação do momento de emergência, que não se confunde com a origem - essa não passa de um efeito exercido sobre a própria fala. Versa, portanto, sobre a irrupção discursiva de um problema, a entrada de forças no confronto discursivo pela naturalização de uma ideia ou prática e privilegia detalhes e acidentes, investindo numa compreensão não linear de eventos descontínuos (FOUCAULT, 1984, p. 77-84).

A genealogia foi anteriormente utilizada na historiografia do ensino musical português, tendo sido identificado o surgimento do génio como tecnologia discursiva responsável pela rarefação das práticas escolares e a divisão elitista das populações de aprendizagem, de acordo com seu contexto social a partir do final do século XIX até o início do século XX (GOMES, 2002; Ó; MARTINS; PAZ, 2013; PAZ, 2014). Com base nessas aproximações teóricas e empíricas, intentamos isolar formações discursivas através do cercamento de longas séries de fontes onde se descortinam ideias pedagógicas, sobre as quais se alicerça o moderno ensino musical.

Por volta de 1870 e até 1930 introduz-se no sistema educativo e musical português este conceito governamental, visível em publicações como a legislação, manuais de ensino e educação musical, artigos e crónicas da imprensa musical e pedagógica e monografias dedicadas a este ramo educativo. Este 
corpus documental ilustrou como a biopolítica contém também uma dimensão estética onde a diferença é produzida de forma a trazer e logo de seguida anular a possibilidade de ser diferente.

A investigação começou por observar a separação permanente entre os que acedem e os são barrados ao mundo das práticas musicais, mas, numa segunda etapa observou-se uma dúvida. Os objetivos políticos assumiam tecnologias do eu, referentes a diferentes populações; tratava-se ora de génio ora nacional e coletivo, ora musical strictu sensu e individualizado. Seria uma única tecnologia ou uma técnica bifurcada?

\section{Educação musical no canto coral: a produção do nacional}

Desde o terceiro quartel do século XIX, o Estado lusitano dava os primeiros passos na educação musical, e, durante as três primeiras décadas do século $\mathrm{XX}$, o sistema educativo incorporou objetivos diversificados para cada um dos ramos e níveis de ensino. O canto coral serviu um dos principais objetivos funcionais do dispositivo escolar de rarefação, uma vez que a sua extensão, nas classes de ensino primário e secundário, permitia uma democratização do ensino musical, desejada pelo Estado, enquanto, ao mesmo tempo, impedia a expansão do ensino especializado.

A educação musical no ensino primário direcionou-se de raiz para o canto coral, sendo de destacar uma tentativa de lançar esta prática nas classes masculinas dos primeiros dos anos (1. ${ }^{\circ}$ grau, decreto de 1870/viii/16), depois transferida para os últimos dois anos $\left(2 .^{\circ}\right.$ grau, carta de lei de $1878 / \mathrm{v} / 2$, regulamentada pelo decreto de 1881/vii/28). Repetidamente se intentou lançar um programa curricular, que só veio a efetivar-se mais tarde, já o regime republicano instaurado em 1910 cumpria meia dúzia de aniversários. O consenso sustentou-se sobre a falta de instituições e currículos de canto coral, dentro e fora da escola primária, secundária, normal e até das universidades. A falta permitiu que, no tempo que decorreu até cerca de 1920, todas as práticas fossem abraçadas. Ao contrário do que aconteceu noutros países (inter alia, SARGEANT, 2010, p. 601-608), inicialmente os principais especialistas de música, em conjunto e sem olhar a dissensões políticas e estéticas, lutaram ativamente pela introdução do canto coral.

O olhar sobre as práticas de canto orfeónico nas nações estrangeiras serviu de mote e argumento para a identificação dessa lacuna. Por exemplo em 1881, o médico e entusiasta da arte de Euterpe, Afonso Vargas publicava um teste- 
munho da vinda de um grupo de estudantes suecos a Portugal, os quais foram aplaudidos como tendo um "dom especial e privilegiado". Chegou-se porém à conclusão que se tratava de "uma simples questão de estudo e de prática". Fora, afinal, "a aula primária o local onde se operara este prodígio" (VARGAS, 1881, p. 1), evidenciando uma prática que era facilmente acessível aos portugueses.

Um dos relatos mais pormenorizados desta falta de um canto coral nas escolas encontra-se no folheto A música portuguesa, preparado por Manuel Ramos num balanço geral sobre a música portuguesa e publicado em 1892 com destino à apresentação na Exposição Pedagógica de Madrid. Começava o musicólogo por expor a situação do ensino primário, secundário, normal e especializado. Como bem observou, as medidas de educação musical escolar eram de caráter muito vago, "verdadeiras prescrições e conselhos ao professor", muito contrárias ao espírito detalhado da jurisprudência portuguesa. Mostravam que, desde a sua raiz, o objetivo de introduzir o canto coral no ensino primário "não visa a formar cantores ou músicos", mas antes "a melhorar as condições físicas das crianças, robustecer os pulmões e os órgãos de fonação, cultivar e aperfeiçoar o ouvido" (RAMOS, 1892, p. xxiii). Não existia qualquer projeto de destinar à vida artista os que apenas frequentassem o ensino primário: "O ensino musical, não existindo nas escolas elementares, e tendo apenas existência legal e não de fato nas escolas complementares", podia "considerar-se nulo e inacessível para o povo" (RAMOS, 1892, p. xxvi), o "ensino musical do povo" era "ainda um mito", concluindo assim que a música portuguesa só poderia jazer "nas camadas à espera que o génio que se inspire nela, rompendo com todos os preconceitos e a torne querida de todos" (RAMOS, 1892, p. xxxii).

A defesa do canto coral permaneceu, nesta época, ligada ao que Gaztambide-Fernández (2013) designa por retórica dos efeitos, sendo avançados argumentos acerca da eficácia da música cantada em coro. Um dos testemunhos mais completos desta visão foi-nos deixado por Emílio Lami, músico e antigo professor de canto coral na Real Casa Pia de Lisboa - o orfanato estatal e uma das poucas escolas onde essa disciplina funcionou ainda durante a monarquia constitucional. Em 1905, divulgou o relatório realizado para o governo sobre a utilidade do canto coral no ensino primário, onde defendia a vantagem de instituir o canto coletivo nas escolas primárias. Lami argumentava, de acordo com a literatura expert e com a sua própria observação das classes onde se ensinava canto coral, tal se fazia "já de há muitos anos nas escolas primárias de todo o mundo" que os benefícios sobre os alunos estavam "higienicamente, intelectualmente, moralmente e disciplinarmente" comprovados (LAMI, 1905, p. 110; grifo do autor).

Apesar deste efeito, tanto pelo que nos indicam os estudos prosopográfi$\cos$, quanto pelo que os músicos nos deixaram grafado, o canto coral não teve 
qualquer influência nos destinos dessoutros indivíduos consagrados como os génios da música portuguesa. O compositor e maestro Fernando Lopes-Graça recorda como as aulas de canto coral em nada o habilitaram musicalmente, nem sequer para a integração com os alunos da sua escola no coro dirigido pelo tenente Rocha, chefe da banda militar do batalhão 15, e que estimamos terem ocorrido por volta de 1916. Era suposto ter-se ensaiado, todas as tardes depois das aulas, o Hino do Contestabre, mas Fernando e seus "compinchas" passaram o tempo "na pagodeira", sem qualquer atenção aos ensinamentos do bom mestre. Como resultado, as "vozes discordantes" salientaram-se de tal modo que foram apenas integrados no espetáculo final "com a advertência de não abrir o bico" (LOPES-GRAÇA, 1973, p. 18-21). Com este jeito anedótico, o autor das composições corais mais impactantes do século XX português não reconhece na formação escolar qualquer acumulação para o seu futuro.

A vitória simbolicamente marcada pelo reforço do canto coral na legislação que, entre 1916 e 1918, renovou os currículos do ensino normal, infantil, primário e liceal, permitiu que se passasse de uma luta consensual pela institucionalização a uma fase de discussão sobre o núcleo das aprendizagens, visível, por exemplo, nas diferentes abordagens manualísticas. A partir da nova legislação republicana e até à homogeneização conseguida a pulso pelo Estado Novo veio fechar este ciclo de expansão do mínimo para atingir o máximo o decreto ${ }^{\circ} 16.730$, de 13 de abril de 1929, que aprovou e publicou novos programas do ensino primário elementar, com a introdução do canto coral para todas as classes: "Rodas e cantos muito simples, a uma voz, aprendidos por audição. Exercícios corais de uma voz. O hino nacional."

As escolas do magistério primário, estipuladas também na reforma da instrução primária (decreto 1870/viii/16) e regulamentadas dez anos depois do seu início (decreto de 1880/vii/28), tiveram um franco impacto no desenvolvimento do ensino musical. Embora o decreto de 24 de dezembro de 1901 e o subsequente decreto de 18 de outubro de 1902 mostrem que não foi aplicável o plano inicial, num difícil acordo entre projeto legal e prática pedagógica, inicia-se uma fase ascendente. A partir do decreto de 4 de dezembro de 1902, voltava a estabelecer-se os programas para o ensino em crescente complexificação, até ao seu auge já na era republicana, pelo decreto $\mathrm{n}^{\circ} 2.213$, de 10 de fevereiro de 1916 , e que acompanha assim a reforma dos programas do ensino primário, estabelecida no decreto $\mathrm{n}^{\circ} 2.887$, de 5 de dezembro de 1916. Fechava-se este ciclo com o decreto $\mathrm{n}^{\mathrm{o}} 18.643$, de 19 de julho de 1930, retificado em 7 de agosto de 1930 . Nele se instituíram as escolas do magistério primário, destinadas à preparação do professorado primário, elementar e infantil, em substituição das escolas normais primárias. Posteriormente, o regime do Estado Novo procurou implementar 
políticas nacionalistas, em que o canto coral teria o papel de unificar o povo, sem maiores especificações acerca da questão musical. (BARREIROS, 1999).

O fundamental viria, porém, a esgrimir-se no cenário do ensino liceal, onde se esperava preparar a vanguarda cultural da nação. Inicialmente, o canto coral aparece incluído apenas no ensino secundário feminino, numa conjunção de aprendizagem de canto coral, com primícias teóricas, solfejo e a possibilidade de usar um instrumento. A experiência iniciada com a população feminina do Liceu Maria, em Lisboa (decreto de 1906/i/31), foi dilatada a outras instituições, como o Instituto Feminino de Educação e Trabalho (decreto $\mathrm{n}^{\mathrm{o}}$ 1.086, de 1915/ix/4). Mas ao ampliar a educação musical ao universo da população liceal (decreto $\mathrm{n}^{0} 4.650$, de 1918/vii/14), estipulou-se que disciplina se cingiria à prática de canto coral. A cumprir esta determinação, o decreto ${ }^{\circ} 4.799$, de 8 de setembro de 1918, aprovava o regulamento de instrução secundária, onde se pode observar um currículo detalhado. $\mathrm{O}$ decreto $\mathrm{n}^{\circ} 7.558$, de 18 de junho de 1921, que dava novo regulamento à instrução secundária, mantinha a obrigatoriedade da disciplina. A fechar este ciclo do ensino secundário refira-se o decreto $\mathrm{n}^{\mathrm{o}} 12.594$, de 2 de novembro de 1926, que aprovava os programas da instrução secundária e o decreto $\mathrm{n}^{\mathrm{0}} 18.885$, de 27 de setembro de 1930, que remodelava todo este nível de ensino.

A história da implementação do ensino de canto coral teve na sua origem, como se pôde observar a breve trecho, uma linha de pensamento governativo de cariz liberal, que procurava salvaguardar a integridade física e moral dos portugueses - tendo começado, aliás, com as preciosas portuguesas - as filhas das classes médias-altas que frequentavam os liceus de Lisboa e depois do Porto. Durante a expansão do canto coral, reclamada em todo o século XIX e efetivada com bastantes reticências durante o período republicano, emergiram questões pedagógicas, possivelmente mantidas sob tensão há muitos anos e que respeitavam a legitimidade de certos métodos e as finalidades que com eles se desejaria obter. As metodologias de ensino, nomeadamente os rudimentos de teoria e solfejo tradicionalmente aplicados, mostravam-se incapazes de servir de suporte a uma prática coral em que se demandava emoção. A educação do sentimento, nomeadamente cívico, fora a promessa do Estado, seguindo indicações de cientistas e peritos. Nesse sentido, o canto coral entra diretamente na tradição europeia de música pela via da fabricação emoção, e por oposição à mathesis, ou forma mais racionalizada da música (EGGEBRECHT, 2009, p. 33-36). Destinava-se a formar em cada um a pertença. 


\section{Ensino especializado: a rarefação dos pianistas ou o músico como génio}

O Conservatório Real de Lisboa foi fundado em 1835 a partir da transição do Seminário da Patriarcal para a Real Casa Pia de Lisboa. Logo de seguida, houve uma reformulação no governo liberal em 1836 e, por decreto de 12 de janeiro de 1837, o Conservatório foi instalado no edifício do antigo Convento dos Caetanos, onde se encontra de portas abertas desde 1838. Não obstante a existência de outras escolas de música privadas, o Conservatório sito em Lisboa foi a principal instituição de formação de instrumentistas e cantores em Portugal. Mesmo com a abertura do Conservatório de Música do Porto em 1917 por iniciativa municipal, a procura de algum tipo de formação musical não cessou de aumentar, o que levou a instituição a lutar na década de 1920 pela compressão populacional. Nesse sentido, deve entender-se como uma opção política o espartilhamento e distribuição do ensino musical pela via de formação de amadores e não de profissionais. Repetidamente, desde final do século XIX, os projetos legais, gizados pelos experts musicais e sancionados pelos governos, passaram pela tentativa de edificar no conservatório o reservatório do futuro escol musical (Ó; MARTINS; PAZ, 2013).

No último dia do ano de 1868 foi assinado o decreto que marcava uma reforma da instrução pública. Daí até 1930, a paisagem legislativa ganhou corpo e podemos contar quatro profundas e detalhadas reformas até à de 1930: em 1887 (carta de lei 1887/viii/25), em 1898 (decreto 1898/i/13), em 1901 (decreto 1901/x/24), e em 1919 (decreto $\left.n^{\circ} 5.546,1919 / v / 9\right)$. Até 1920 a frequência dos estudantes era relativamente baixa e sempre irregular, mas a procura das aulas de música disparou nessa década, para em 1930, ser imposta a medida de $n u$ merus clausus pelo decreto $\mathrm{n}^{\circ} 18.881$, de 25 de setembro de 1930 . Neste setor, as políticas educativas foram estabelecidas pelos experts reconhecidos pelos seus pares, sendo a ingerência estritamente política relacionada sobretudo com a distribuição de recursos, mas nunca relativa às questões pedagógicas e artísticas.

Encontra-se uma verdadeira transição no decreto de 24 de outubro de 1901, que se completa na publicação do novo regulamento interno do Conservatório, pelo decreto de 22 de novembro do mesmo ano. A reforma elaborada pelo escritor e jornalista Eduardo Schwalbach Lucci, então inspetor do Conservatório, e pelo compositor e professor de canto Augusto Machado, diretor da instituição entre 1901 a 1908, uma disposição a "ministrar aos futuros músicos uma cultura menos primária". Com essas palavras, sublinharia o desejo de ver "a educação musical do Conservatório" corresponder "a uma educação de espírito", com o 
estipêndio de novas disciplinas culturais, como História da Música e de Literatura Musical, classes de música de orquestra e de câmara e uma aula de canto coral (BRANCO, 1987, p. 114). No Conservatório, apesar da quebra ocorrida na década coincidente com a Primeira Guerra Mundial, o número de alunos teve um movimento geral ascendente. Nesse contexto, pode afirmar-se que as políticas educativas, nesse setor, investiram sempre na rarefação das oportunidades, argumentando pela necessidade de um ensino de maior qualidade.

Nesse contexto, o ensino do piano tornou-se, até ao final do século XIX, aquele que atraiu mais alunos no Conservatório, concorrendo apenas com a aprendizagem do violino e do canto (lírico) (GOMES, 2002). Desenvolveu-se, em torno desse instrumento, toda uma especificação das técnicas através das quais a tecnologia do génio se conectava ao fenómeno biopolítico: à medida que o aluno ia progredindo, o adestramento corporal ia-o mantendo ou afastando da possibilidade de seguir um percurso artístico. Não seria possível examinar no escopo deste breve analítico todos os pontos nodais que estão implicados no ensino de piano, incluindo a própria alma. Serve portanto de metonímia o adestramento contínuo das extremidades envolvidas na performance pianística, as mãos que abarcam o teclado e os pés que conduzem a sonoridade.

A mão do pianista parecia ter contornos de verdadeiro elo carnal de ligação entre homem e piano. Sobre o piano, começaram a ser divulgados no país os ensinamentos do idolatrado Robert Schumann, ele mesmo tido por um génio: "Os dedos devem executar o que o espírito concebeu" (SCHUMANN, 1898, p. 100). Estabeleceu-se desse modo uma pedagogia do homem-máquina, em que se espera um prolongamento entre pianista e piano, que teria a mão como um centro nevrálgico de musicalidade. Um dos melhores exemplos dessa época encontra-se no manual do pianista editado em 1888 pelo músico e musicólogo alemão Hugo Riemann, citado aqui em tradução nossa a partir da edição 1928. O manual divide-se em três partes, sobre o instrumento, o pianista e a obra musical.

De acordo com esta autoridade, o talento distinguia-se entre o geral e o pianístico, sendo este talento específico detetável pela "estrutura normal da mão", ou, para ser mais preciso, era revelado "em certa constituição anormal precisamente adequada às condições do teclado". Esse fácies manual tinha, naturalmente de ser acompanhado por outras características, como "uma forte musculatura, um sistema nervoso são, um temperamento decidido e uma ausência absoluta de timidez e de apoucamento" e "uma memória mais do que regular". Mas essas seriam já características acrescidas. O busílis da questão, que pela época dividia opiniões, era o que se pode considerar "uma boa mão pianística": "uns estimam os dedos largos, mais enxutos do que carnudos; outros opinam mais favoravelmente por uma mão larga, de dedos curtos e robustos". (RIEMANN, 1928, p. 30-31, tradução nossa). 
Em estudos sobre o uso de biografias de músicos consagrados no ensino artístico, essa técnica tem sido relacionada diretamente com a tecnologia do génio, em concreto como o entalhe desse conceito na normação de caráter pedagógico (PAZ, 2014; MARTINS, 2011). Com efeito, a explicação de Riemann para essa discrepância reside no "facto de haver famosíssimos pianistas, homens e mulheres, com as mais variadas estruturas de mãos" (RIEMANN, 1928, p. 30-31).

A aprendizagem de piano, com consequências para o destino social e profissional, assentava assim em condições físicas específicas para o domínio do teclado. Apesar de toda a panóplia de variantes de teclado que estavam a ser fabricadas e utilizadas (LEÃO, 2012), no ensino conservatorial, permanecia o princípio de ser o humano a adaptar-se ao objeto e não o contrário, situação que conferia vida própria ao instrumento. O musicólogo teutónico via-se assim incapaz de traçar uma regra universal, limitando-se a excluir as características que impossibilitavam alcançar um nível técnico elevado: "dedos débeis que se dobram e torcem facilmente e, em geral, debilidade muscular; fortes membranas interdigitais; união excessivamente robusta e carnosa do polegar com o indicador; inchaço das articulações". Afirmava que o

pianista moderno deve possuir necessariamente uma natureza sã e robusta, pois que, antes de estar em condições de se apresentar ao mundo como artista, o seu corpo teve de resistir a uma dura prova de uma larga série de anos de entretenimento técnico que esgotam a resistência física dos demais. (RIEMANN, 1928, p. 31; grifo do autor).

Tocar piano equivalia assim a um compromisso de devir "atleta do piano". Para tanto, exigiria condições físicas que, embora não excludentes $a$ priori, limitavam a entrada no olimpo a "naturezas de organização delicada". (RIEMANN, 1928, p. 32).

É nesse sentido que, sem uma investigação de fundo, a pedagogia musical surgiu com algumas soluções advindas do solo da experiência. Embora circulassem instrumentos facilitadores na aquisição de uma posição correta (e.g., uso de uma maçã no punho) ou na correção de caraterísticas físicas (e.g., esticadores para os dedos), a literatura pedagógica evitava esse expediente, preferindo analisar o corpo do discípulo a partir da potência do treinamento. Temos alguns exemplos desta normatividade, que se esforça por diluir o dispositivo de rarefação, suspendendo por breves instantes a tecnologia do génio através da incisão de técnicas pedagógicas que apostavam na disciplina corporal - para logo retomar o dispositivo de rarefação. 
Em Portugal, no ano de 1923, a professora e pianista Oliva Guerra (1923b), discípula de Viana da Mota, por sua vez, leitor ávido de Hugo Riemann, detalhou as implicações do ensino pianístico na coluna dirigida a perguntas de leitores, intitulada "Consultório Musical". Entre muitos dos seus aconselhamentos práticos, dirige-se à mãe de uma criança de mãos muito pequenas, dando a entender que havia primeiro que "deixar a menina crescer até que a mão lhe cresça até ao tamanho necessário". Além da natureza, "esse crescimento" poderia ser conduzido "com exercícios de mecanismo de Czerny, Phillipp, de Hannon", usados nos currículos dos mais reputados conservatórios da época, fazendo também exercícios de memória "tentando acompanhar oitavas estendendo a mão o mais possível sobre as teclas e abrindo-as, puxando os dedos" (GUERRA, 1923b, p. 8). Deixava também um aviso, que ilustra perfeitamente como a tecnologia do génio se imiscui aqui nas técnicas pedagógicas: "Se assim não conseguir terá de se convencer que não tem condições físicas para tocar piano. Porque às vezes assim sucede, nem toda a gente pode ser pianista" (GUERRA, 1923b, p. 8; grifo nosso).

Já com o pé, a outra extremidade do corpo que tinha por função a utilização dos pedais, existia uma certa tolerância. Sem pés, o génio estava vedado, mas havia ainda a possibilidade de formar um bom executante, desde que selecionado o repertório adequado. Oliva Guerra atenuava assim a mágoa de uma aspirante que se lamentara de uma diminuição física no pé esquerdo, com o qual: "nunca poderia vir a ser uma pianista comme il faut". Se a consagração não estava no caminho e se a pedagogia em nada poderia fazer retroceder os caprichos da natureza, poderia pelo menos "tocar alguma coisa", pois "se tem o pé esquerdo imobilizado, o que já não pode é servir-se do pedal abafador", indispensável apenas em algumas peças. Poderia, contudo, adestrar-se no uso do "primeiro pedal", que, bem vistas as coisas, "tem uso muito mais continuado do que o outro" (GUERRA, 1923a, p. 8). Porém, e é a este ponto que pretendemos chegar, o argumento era apenas um placebo, pois logo a professora experimentada, sem a desencorajar por completo, mas trazendo de novo o discurso para a égide do génio, oferecia o seguinte conselho: "se tem assim essas aptidões para a música, porque não se consagra antes a outro instrumento - ao violino, ou violoncelo, por exemplo? Ou canto, ou ainda ao estudo da harmonia?". E logo rematava, voluntariosa "Para qualquer destas coisas lhe indicarei eu mesma professor competente", porque afinal: "Nem só de pianistas é o mundo" (GUERRA, 1923a, p.8). 


\section{Fecho: coralista ou pianista, corpos adestrados numa mesma tecnologia}

As tecnologias do eu formuladas no espetro Estatal direcionaram-se, no campo da educação primária, secundária e normalista, para a introdução do dipositivo "génio coletivo", de caráter nacional. Ao mesmo tempo, preparavam os sujeitos para o consumo da produção artística, através de uma outra formulação, o "génio individualizado", que incorporava conhecimentos acessíveis apenas nas formações especializadas de música. Começamos assim por identificar uma bifurcação na ideia de génio. Embora interrelacionados, o génio coletivo e o artista genial não se confundem. A produção destes sujeitos segue uma trajetória diferenciada e, consequentemente, são agilizadas diferentes técnicas de normalização. Para uma comparação mais nítida, escolhemos as duas modalidades de ensino mais em voga em cada um dos ramos de ensino: o canto coral e o piano. De facto, entre final do século XIX e início do século XX, o canto coral, o mais das vezes esvaziado de elementos teóricos, manteve-se quase sempre como a única forma de transmitir ensinamentos musicais no ensino primário e secundário, embora os coros existissem também fora do ambiente escolar, por exemplo, dentro de associações recreativas, e demandassem a presença de crianças em idade escolar. Por sua vez, o piano era a disciplina mais em voga tanto no conservatório oficial quanto na procura de formação no domínio privado e particular.

Em ambas as formações - uma destinada aos sujeitos capazes de reconhecer e sentir a sua nacionalidade, a outra à execução virtuosa de música do repertório erudito de tradição ocidental, e incidindo uma sobre a voz que se treina em coletivo e construindo a outra um atletismo de alta competição - verifica-se a mesma capacidade de produzir nos sujeitos as caraterísticas estéticas que atuam no dispositivo de rarefação das oportunidades musicais. Se o canto coral tem como missão primeira a inclusão nas práticas artísticas, não existe, nem nas diretivas curriculares, nem nos discursos esgrimidos pelos diversos especialistas, nem sequer em testemunhos sobre a época, uma capitalização desta forma artística. Isto é, não se visava produzir um produtor, mas apenas um performer de elevado desgaste e rotatividade. $\mathrm{O}$ aluno convidado a esse exercício não reconhecia a possibilidade de migrar do ambiente escolar para outros cenários artísticos. Na escola, onde era pontualmente compelido a participar destas manifestações, estava direcionado para uma prática eminentemente comemorativa, em que a instituição se mostrava para o exterior, mas sem acoplar às suas práticas aprendizagens significativas. 
Por sua vez, o génio musical que se atribuía a indivíduos estava restrito não apenas a estratos favorecidos em termos socioeconómicos e culturais, mas a caraterísticas físicas. Noutras palavras, a inefabilidade do reconhecimento de quem estava capacitado para aprender música prendia-se afinal a técnicas muito tangentes de identificação/julgamento de quem estava dentro e quem deveria estar fora do ensino musical.

Consideramos, deste modo, que apesar da imagem bífida do génio, a sua articulação num mesmo dispositivo de rarefação que se fazia usar em ambiente escolar, deve ser considerado com uma única tecnologia. Tal como, no mecanismo global da intervenção do Estado na formação artística, servia um único propósito de restringir o ensino a muito poucos e de manter uma educação mais alargada à massa de indivíduos que se foram escolarizando. Fazendo uma ponte com o presente, talvez, por hipótese, essa característica possa explicar a divisória que nos países de tradição latina se mantém, entre ensino e educação musical, entre uma disciplina de música que forma ouvintes e disciplinas que objetivam a possibilidade de tratar com instrumentos.

\section{REFERÊNCIAS}

AGAMBEN, G. O que é o contemporâneo? E outros ensaios. Chapecó: Argos, 2009.

BARREIROS, M. J. A. A disciplina de canto coral no periodo do Estado Novo. Dissertação em Ciências Musicais. Lisboa: Universidade Nova de Lisboa, 1999.

BRANCO, J. de F. Viana da Mota. 2. ed. Lisboa: Fundação Calouste Gulbenkian, 1987. CABELEIRA, H. O Artista enquanto Aluno (1878-2007). 2013. Tese em Educação. Lisboa: Universidade de Lisboa, 2013.

EGGEBRECHT, H. H. Conceito de música e tradição europeia. In: DAHLHAUS, C.; EGGEBRECHT H. H. Que é a Música?. Lisboa: Edições Texto \& Grafia, 2009. p. 29-36.

FOUCAULT, M. Nietzsche, genealogy, history. In: RABINOW, P. The Foucault Reader. Nova Iorque: Pantheon, 1984. p. 76-97.

FOUCAULT, M. A vontade de saber. In: FOUCAULT, M. História da sexualidade. Coleção Ditos e escritos, vol. 1. Lisboa: Relógio d’Água, 1994.

FOUCAUlT, M. Em defesa da sociedade. São Paulo: Martins Fontes, 1999.

FOUCAULT, M. Vigiar e punir. História da violência nas prisões. Petrópolis: Editora Vozes, 2004. 
FOUCAULT, M. A 'governamentalidade'. In: FOUCAULT, M. Estratégia poder-saber. Coleção Ditos e escritos, vol. 4. Trad. MOTTA, M. B. Rio de Janeiro: Forense Universitária, 2006. p. 281-305.

GAZTAMBIDE-FÉRNANDEZ, R. Why the Arts Don't Do Anything: Toward a New Vision for Cultural Production in Education. Harvard Educational Review, vol. 83, n. 1, Primavera, p. 211-236, 2013.

GOMES, C. Discursos sobre a "especificidade” do ensino artístico: a sua representação histórica nos séculos XIX e XX. 2002. Dissertação em Educação. Lisboa: Universidade de Lisboa, 2002.

GUERRA, O. Consultório musical. A Semana Musical, Lisboa, n. 20, p. 8, 24 maio, 1923 a. GUERRA, O. Consultório musical. A Semana Musical. Lisboa, n. 21, p. 8, 31 maio, $1923 b$.

LAMI, E. O canto coletivo nas escolas primárias. A Arte Musical, Lisboa, ano viii, n. 153, p. 109-110, 15 maio 1905.

LEÃO, R. S. Considerações sobre diversos modelos de ensino de piano. 2012. Dissertação em História Social do Piano. Almada: Instituto Piaget, 2012.

LOPES-GRAÇA, F. Disto e daquilo. Lisboa: Cosmos, 1973.

MARTINS, C. As narrativas do génio e da salvação. 2011. Tese em Educação. Lisboa: Universidade de Lisboa, 2011.

Ó, J. R. do. O governo de si mesmo: Modernidade pedagógica e encenações disciplinares do aluno liceal (último quartel do século XIX - meados do século XX). Lisboa: Educa, 2003.

Ó, J. R. do; MARTINS, C. S.; PAZ, A. L. Genealogy as History. In: POPKEWITZ, T. (Ed.). (Re)visioning The History of Education. Nova Iorque: Palgrave, 2013. p. 157-178.

PAZ, A. L. Ensino da Música em Portugal (1868-1930). 2014. Tese em Educação. Lisboa: Universidade de Lisboa, 2014.

RAMOS, M. A música portuguesa. Porto: Imprensa Portuguesa, 1892.

RIEMANN, H. Manual del pianista. Barcelona/Buenos Aires: Labor, 1928.

RUDDOCK, E.; LEONG, S. 'I am unmusical!': The verdict of self-judgment. International Journal of Music Education, n. 23, p. 9-22, 2005.

SARGEANT, L. Whoever can speak, can sing. Paedagica Historica, vol. 46, n. 5, p. 601-622, 2010.

SCHUMANN, R. Aforismos sobre a música. Amphion. Lisboa, ano v, n. 13, p. 100, $1^{\circ}$ jul. 1898.

SERRES, M. Ramos. Lisboa: Instituto Piaget, 2005. 
PAZ, A. L.; Ó, J. R. do. A pedagogia artística como normação da vida: tecnologias do eu...

VARELA, J. Genealogy of education. In: POPKEWITZ, T.; FRANKLYN, B.; PEREYRA, M. Cultural History and Education. Nova Iorque: Routledge Falmer, 2001. p. 109-124.

VARGAS, A. O canto coral no ensino. Perfis Artísticos, Lisboa, ano I, n. 6, p. 1-2, out. 1881.

Texto recebido em 02 de julho de 2017. Texto aprovado em 03 de julho de 2017. 